\title{
Infliximab biosimilar CT-P13 is effective and safe in treating inflammatory bowel diseases: a real-life multicenter, observational study in Italian primary inflammatory bowel disease centers
}

\author{
Antonio Tursi ${ }^{a}$, Giammarco Mocci ${ }^{b}$, Roberto Faggianic, Leonardo Allegrettad, Nicola Della Vallee,

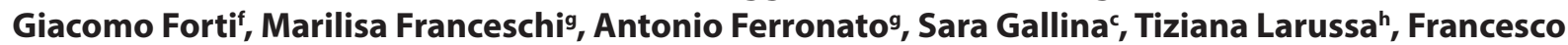 \\ Luzzah', Roberto Lorenzetti', Antonio Pennaj, Stefano Rodino ${ }^{k}$, Ladislava Sebkovak, Angelo Lauria', \\ Simona Piergallini ${ }^{m}$, Giuseppe Pranzon ${ }^{n}$, Cristina Ricciardellio, Costantino Zampalettac, Walter Elisei ${ }^{\mathrm{p}}$, \\ Marcello Picchio ${ }^{q}$
}

ASL BAT, Andria; Brotzu Hospital, Cagliari; Belcolle Hospital, Viterbo; Santa Caterina Novella Hospital, Galatina, LE; Ospedali Riuniti, Foggia; S. Maria Goretti Hospital, Latina; ULSS7 Pedemontana, Santorso, VI; University of Catanzaro; PTP Nuovo Regina Margherita, Rome; S. Paolo Hospital, Bari; Ciaccio-Pugliese Hospital, Catanzaro; A.O. BianchiMelacrino-Morelli, Reggio Calabria; A. Murri Hospital, Fermo; Valle D’Itria Hospital, Martina Franca, TA; Veris Delli Ponti Hospital, Scorrano, LE; ALS Roma 6, Albano Laziale, Roma; P. Colombo Hospital, Velletri, Roma, Italy

Abstract

aTerritorial Gastroenterology Service, ASL BAT, Andria (Antonio Tursi); 'Division of Gastroenterology, "Brotzu” Hospital, Cagliari (Giammarco Mocci); 'Division of Gastroenterology, "Belcolle" Hospital, Viterbo (Roberto Faggiani, Sara Gallina, Costantino Zampaletta); dDivision of Gastroenterology, "Santa Caterina Novella" Hospital,

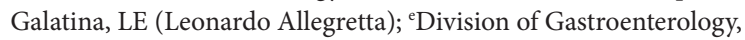
A.O. "Ospedali Riuniti”, Foggia (Nicola Della Valle); 'Division of Digestive Endoscopy, "S. Maria Goretti” Hospital, Latina (Nicola Della Valle, Giacomo Forti); ${ }^{\mathrm{D} D i g e s t i v e ~ E n d o s c o p y ~ U n i t, ~ U L S S 7 ~}$ Pedemontana, Santorso (VI) (Marilisa Franceschi, Antonio Ferronato); ${ }^{\mathrm{h}}$ Department of Health Science, University of Catanzaro, Catanzaro gastroenterology centers. clinical remission.
Background The purpose of this study was to assess the efficacy and safety of biosimilar infliximab (IFX) CT-P13 in treating outpatients with inflammatory bowel disease (IBD) in Italian primary

Methods Consecutive IBD outpatients who completed the induction treatment were evaluated retrospectively. Clinical activity was scored according to the Mayo score for ulcerative colitis (UC) and to the Harvey-Bradshaw Index (HBI) for Crohn's disease (CD). The primary endpoint was the achievement of clinical remission (Mayo score $\leq 2$ in $\mathrm{UC}$ and $\mathrm{HBI} \leq 5 \mathrm{in} \mathrm{CD}$ ). Secondary endpoints were clinical response to treatment, achievement of mucosal healing, and safety. with anti-tumor necrosis factor (TNF) a had been provided to $26 \%$ of UC patients and $28.9 \%$ of CD patients. Remission was achieved in $57.3 \%$ UC patients and in $75.6 \%$ CD patients during a median (interquartile range) follow up of 24 (6-24) months. Clinical response and mucosal healing were achieved in $87.5 \%$ and $75.0 \%$ of UC patients and in $84.4 \%$ and $84.2 \%$ of CD patients, rectively. By both univariate and multivariate analysis, age $>40$ years, presence of comorbidities, and naivety to anti-TNFa were significantly related to remission. Only one (0.7\%) adverse event was reported in the CD group. Surgery was performed in $2.1 \%$ of UC patients and $6.7 \%$ of CD

Conclusion This study confirmed the long-term efficacy and safety of CT-P13 therapy in IBD, in both naïve patients and those switching from IFX originator.

Keywords Biosimilar, CT-P13, Crohn's disease, infliximab, ulcerative colitis

Ann Gastroenterol 2019; 32 (3): 1-8

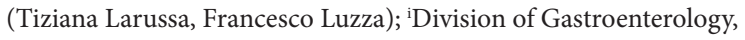
PTP “Nuovo Regina Margherita”, Rome (Roberto Lorenzetti); 'Division of Gastroenterology, "S. Paolo" Hospital, Bari (Antonio Penna);

Conflict of Interest: None

Correspondence to: Antonio Tursi, MD, Via Torino 49, 76123 Andria, BT, Italy, e-mail: antotursi@tiscali.it

Received 13 February 2019; accepted 1 April 2019; published online 22 April 2019

DOI: https://doi.org/10.20524/aog.2019.0377 


\section{Introduction}

Inflammatory bowel diseases (IBD) are mainly represented by ulcerative colitis (UC) and Crohn's disease (CD). Both diseases arise from an interaction between genetic and environmental factors, and they are predominantly observed in developed countries [1]. Both UC and CD are characterized by a relapsing and remitting course, sometimes requiring an aggressive therapeutic approach to prevent complications [2]. The discovery that tumor necrosis factor (TNF)a plays an important role in the pathogenesis of IBD [1] and the introduction of the monoclonal anti-TNFa antibody infliximab (IFX) have greatly improved treatment options in IBD patients refractory to or intolerant of standard therapies [2,3], for either CD or UC [1].

Obviously, this treatment entails a much higher financial burden than do traditional therapies [4-6]. In response to the often high costs of originator biologics, interest has grown in biosimilar alternatives, which are cost-effective, "follow-on" biologic drugs with highly similar quality, efficacy, and safety compared to an already licensed biologic [6,7]. Biosimilar IFX CT-P13 (Remsima ${ }^{\mathrm{TM}}$, Inflectra ${ }^{\mathrm{TM}}$ ) is a biosimilar alternative to the IFX "reference medicinal product" (RMP) (Remicade ${ }^{\mathrm{TM}}$ ) and is the first monoclonal antibody biosimilar to be approved by the European Medicines Agency. Biosimilar IFX CT-P13 and the IFX RMP are chimeric monoclonal IgG1 antibodies, produced in independently developed cell lines, derived from the same murine hybridoma cell type [8].

After the first positive experiences in rheumatic diseases $[9,10]$, biosimilar IFX CT-P13 was approved for all of the same indications as the RMP, including CD and UC, in Europe, Japan and South Korea $[8,11,12]$. Subsequently, several recent studies found biosimilar IFX CT-P13 to be effective and safe in patients with CD or UC [13-23], and a recent position paper from the European Crohn's and Colitis Organization states that biosimilar IFX can be expected to have the same efficacy and safety as the originator [24]. However, the vast majority of the studies were performed in secondary or tertiary centers [11-23].

IFX CT-P13 reimbursement for CD and UC was approved in Italy in 2014 [24,25]. Two Italian studies have investigated the efficacy and safety of this IFX biosimilar. However, the short follow up [15,23] and the small sample enrolled [26] limited the impact of these studies. The aim of the present study was to assess the efficacy and safety of biosimilar IFX CT-P13 in treating a large IBD outpatient population in some

${ }^{k}$ Division of Gastroenterology, "Ciaccio-Pugliese" Hospital, Catanzaro (Stefano Rodino, Ladislava Sebkova); 'Division of Gastroenterology, A.O. "Bianchi-Melacrino-Morelli”, Reggio Calabria (Angelo Lauria); ${ }^{m}$ Division of Gastroenterology, IBD Unit, "A. Murri” Hospital, Fermo (Simona Piergallini); "Ambulatory for IBD Treatment, "Valle D'Itria" Hospital, Martina Franca (TA) (Giuseppe Pranzo); ${ }^{\circ}$ Division of Gastroenterology, "Veris Delli Ponti" Hospital, Scorrano (LE) (Cristina Ricciardelli); ${ }^{\mathrm{p} D i v i s i o n}$ of Gastroenterology, ASL Roma 6, Albano Laziale, Rome (Walter Elisei); "Division of General Surgery, "P. Colombo" Hospital, ASL Roma 6, Velletri, Rome (Marcello Picchio), Italy
Italian primary IBD centers, following approval of biosimilar IFX CT-P13 reimbursement for IBD by the Italian Regulatory Authorities.

\section{Patients and methods}

This was a retrospective, observational, multicenter study that included outpatients with UC or CD unresponsive to standard treatments and were treated with biosimilar IFX CTP13 $\left(\right.$ Remsima $^{\mathrm{TM}}$ ) in 14 Italian primary IBD centers (namely, centers identified by the Italian National and Regional Health Systems as able to manage uncomplicated IBD patients). We assessed patients enrolled from $1^{\text {st }}$ May 2015 to $31^{\text {st }}$ December 2017, who completed at least the induction treatment. Eligible patients included men and women, at least 18 years of age, with an established diagnosis of UC or CD according to standard endoscopic and/or radiology and/or histological criteria [1].

A shared common database was used to collect demographic and clinical data. Data collected at baseline were sex, age at diagnosis, smoking status, disease extension, disease duration, previous immunosuppressive and anti-TNFa therapies, concomitant medications at baseline, C-reactive protein and fecal calprotectin levels, Mayo score and Mayo subscore for endoscopy for UC patients, and Harvey-Bradshaw Index (HBI) for CD patients. Patients were clinically assessed at entry, after $2,3,6$, and then every 6 months.

All procedures performed in studies involving human participants were in accordance with the ethical standards of the institutional and/or national research committee and with the 1964 Helsinki declaration and its later amendments or comparable ethical standards. All patients gave written informed consent before undergoing endoscopy and IFX CT-P13 treatment. Formal consent is not required for this type of study.

\section{Study treatment}

All patients were eligible for infusion of biosimilar IFX after exclusion of active hepatitis B virus infection, active cytomegalovirus infection, and tuberculosis infection. After pre-treatment with methylprednisolone $20 \mathrm{mg}$ intravenously (or chlorphenamine $10 \mathrm{mg}$ intramuscular in patients intolerant of steroids) at every infusion, biosimilar IFX CTP13 $\left(\right.$ Remsima $\left.^{\mathrm{Tu}}\right)$ was administered at a dose of $5 \mathrm{mg} / \mathrm{kg}$ via $2-\mathrm{h}$ intravenous infusion at weeks 0,2 , and 6 in order to obtain remission, and thereafter every 8 weeks in order to maintain remission. Dose escalation to maintain remission, namely an infusion regimen increasing to $10 \mathrm{mg} / \mathrm{kg}$ and/or every 4 instead of 8 weeks, was applied when necessary. If dose escalation was applied, it was recorded and reported.

The need for treatment discontinuation was left to the investigators' judgement, as were concomitant medications including oral and topical aminosalicylates, steroids and immunosuppressants. 


\section{Clinical assessment}

Disease extension was assessed according to the Montreal classification [27]. Severity was assessed according to the Mayo score [25] in UC patients and according to HBI [28] score in $\mathrm{CD}$ patients. All patients had active disease despite concomitant treatment, defined as a Mayo score $\geq 3$ points [29] for UC patients and an HBI score $>5$ points [11] for CD patients. As stated, patients were clinically assessed at entry, after 2, 3, 6, and then every 6 months.

\section{Endoscopy}

As standard protocol for patients under treatment with biologics in the participating centers, ileocolonoscopy was performed in all enrolled patients at entry, after 6,12 , and every 12 months thereafter during treatment. CD patients with an upper gastrointestinal location underwent both esophagogastroduodenoscopy and ileocolonoscopy, both at diagnosis and during the follow up.

Endoscopic severity in UC patients was assessed according to the Mayo subscore for endoscopy [29]. Endoscopic severity in $\mathrm{CD}$ patients was assessed by the simple endoscopic score for CD (SES-CD) [30,31].

\section{Endpoints}

Primary endpoints were: a. induction of remission, defined as Mayo score $\leq 2$ in UC patients and $\mathrm{HBI} \leq 5$ in CD patients; and b. safety of biosimilar IFX CT-P13, defined as absence of adverse events (AE) during treatment. The AE were subdivided into early (occurring during infusion) and late (occurring at least one week after the infusion) events, and were graded as mild (not requiring cessation of treatment) and severe (requiring cessation of treatment). The occurrence of opportunistic infections was also considered as an AE. An opportunistic infection was defined as any infection caused by microorganisms that have limited pathogenic capacity under normal circumstances, but that have been able to cause disease because of the predisposing effect of another disease or its treatment [32].

Secondary endpoints were: a. clinical response, defined as reduction of at least 2 points in the Mayo score in UC patients and at least 3 points in the HBI score in CD; b. achievement of mucosal healing, defined as Mayo subscore for endoscopy $\leq 1$ in UC and SES-CD score $\leq 2$ in CD; c. reduction in steroid use during the study; d. prevention of colectomy in UC and any surgical procedure related to the disease in $\mathrm{CD}$; and e. assessment of any difference between patients naïve to IFX and patients switching from Remicade ${ }^{\mathrm{m} m}$ to Remsima ${ }^{\mathrm{m}}$.

\section{Statistical analysis}

Data were analyzed using MedCalc ${ }^{\oplus}$ Release 14.8.1. The characteristics of the study group were analyzed as median (interquartile range $[\mathrm{IQR}]$ ) for continuous non-parametric variables and as number (percentage) for categorical variables. Fisher's exact test was used to compare categorical variables. Clinical remission was considered as the primary endpoint. The prognostic value of clinical parameters was evaluated using time-to-event methods for censored observations, because of the varying length of follow up. Follow-up times were calculated from the date of diagnosis to the date of event or censorship. Time-to-event analysis was carried out using Kaplan-Meier estimates to draw the cumulative incidence curves, compared by log-rank tests, as well as by univariate and multivariate Cox's proportional hazards models of prognostic variables. The hazard ratios are presented with $95 \%$ confidence intervals and P-values. A ratio higher than unity implies that an event has a higher probability compared to the reference group. P-values $<0.05$ were considered to be statistically significant.

\section{Results}

One hundred forty-one patients were enrolled according to the inclusion criteria. The characteristics of the study group according to UC and CD are reported in Table 1. Both groups were similar with respect to demographic and clinical characteristics. The majority of patients enrolled in both groups were naïve to anti-TNFa (26\% of UC patients and $28.9 \%$ of $\mathrm{CD}$ patients were previously treated with anti-TNFa). Patients previously treated with anti-TNFa were enrolled because of a secondary loss of response to the treatment in the majority of subjects in both groups.

\section{Primary endpoints}

Overall, remission was achieved in 55 of 96 (57.3\%) UC patients and in 34 of $45(75.6 \%)$ CD patients during a median (IQR) follow up of 24 (6-24) months, with no significant difference (Fig. 1). In patients previously exposed to antiTNFa, remission was achieved in 12 of 25 (48.0\%) UC patients and in 8 of 13 (61.5\%) CD patients. By both univariate and multivariate analysis, age over 40 years, the presence of comorbidities and naivety to anti-TNFa were significantly related to remission (Table 2 ).

With respect to safety, only one (0.7\%) AE was reported in the CD group. It was a mild skin atopic reaction that occurred in a 21-year-old male at the first biosimilar IFX CT-P13 infusion and led to prompt interruption of the treatment.

\section{Secondary endpoints}

Secondary end-points are shown in Table 3. All parameters assessed showed significant efficacy of biosimilar IFX CT-P13. In particular, achievement of mucosal healing and steroid withdrawal during the follow up showed very high percentages, confirming the efficacy of this biosimilar drug. Finally, all the 
Table 1 Demographics, disease characteristics and concomitant medications

\begin{tabular}{|c|c|c|}
\hline Characteristics & UC $(n=96)$ & $\mathrm{CD}(\mathrm{n}=45)$ \\
\hline Male sex & $46(47.9)$ & $21(46.7)$ \\
\hline Mean $(95 \% \mathrm{CI})$ age, years & $46.5(43.7-49.3)$ & $39.1(34.6-43.7)$ \\
\hline Median (IQR) disease duration, years & $5(3-13)$ & $4(3-9)$ \\
\hline Presence of comorbidities & $31(32.3)$ & $16(35.6)$ \\
\hline Previous appendectomy & $6(6.2)$ & $8(17.8)$ \\
\hline \multicolumn{3}{|l|}{ Concomitant therapy } \\
\hline Mesalazine & $93(96.9)$ & $42(93.3)$ \\
\hline Steroids & $94(98.9)$ & $43(95.6)$ \\
\hline Thiopurine & $3(3.2)$ & $2(4.4)$ \\
\hline Previous anti-TNF $\alpha$ & $25(26.0)$ & $13(28.9)$ \\
\hline Adalimumab & $7(28.0)$ & $8(61.5)$ \\
\hline Golimumab & $18(72.0)$ & $5(38.5)$ \\
\hline Primary non-responders & $7(28.0)$ & $1(7.7)$ \\
\hline Secondary loss of response & $18(72.0)$ & $12(92.3)$ \\
\hline \multicolumn{3}{|l|}{ Montreal classification of extent of UC } \\
\hline Left-sided colitis & $28(29.1)$ & - \\
\hline Extensive colitis & $67(69.9)$ & - \\
\hline \multicolumn{3}{|l|}{ Montreal classification of CD } \\
\hline Isolated ileal disease & - & $19(42.21)$ \\
\hline Isolated colonic disease & - & $11(24.4)$ \\
\hline Ileocolonic disease & - & $15(33.3)$ \\
\hline Concomitant UGI disease & - & - \\
\hline Concomitant perianal disease & - & $9(20.0)$ \\
\hline Non stricturing, non-penetrating & - & $20(44.4)$ \\
\hline Stricturing & - & $17(37.8)$ \\
\hline Penetrating & - & $8(17.8)$ \\
\hline Median (IQR) CRP, (mg/L) & $16.0(8.7-28.5)$ & $15.0(7.0-30.0)$ \\
\hline Median (IQR) fecal calprotectin $(\mu \mathrm{g} / \mathrm{g})$ & $340(240-645)$ & $485.0(203.2-856.5)$ \\
\hline Median (IQR) partial Mayo score & $7(6-8)$ & - \\
\hline Median (IQR) Mayo subscore for endoscopy & $3(2-3)$ & - \\
\hline Median (IRQ) HBI & - & $10(6-15)$ \\
\hline Median (IRQ) SES-CD & - & $10(7-14)$ \\
\hline
\end{tabular}

Data are given as number (percentage) of patients unless otherwise indicated

$I Q R$, interquartile range; CRP, C-reactive protein; HBI, Harvey-Bradshaw index; SES-CD, simple endoscopic score for Crohn's disease; TNF, tumor necrosis factor; UGI, upper gastrointestinal

parameters assessed were reported with similar percentages in both UC and CD patients.

With respect to surgery, colectomy was performed in 2 (2.1\%) UC patients at 1 and 6-month follow up, and ileocolic resection in $3(6.7 \%)$, at 2,3 and 18 -month follow up.

Finally, a switch from IFX originator to IFX biosimilar occurred in 22 patients ( $15.6 \%$ of the overall population): 15 (15.6\%) UC patients and 7 (15.5\%) CD patients. All these patients were under stable remission at the time of switching, performed with a view to significant cost saving.
As reported in Table 2, switching from IFX originator to biosimilar did not influence the maintenance of the remission.

\section{Discussion}

Biosimilars have been developed because they entail a much lower financial cost than that for traditional treatment options. 


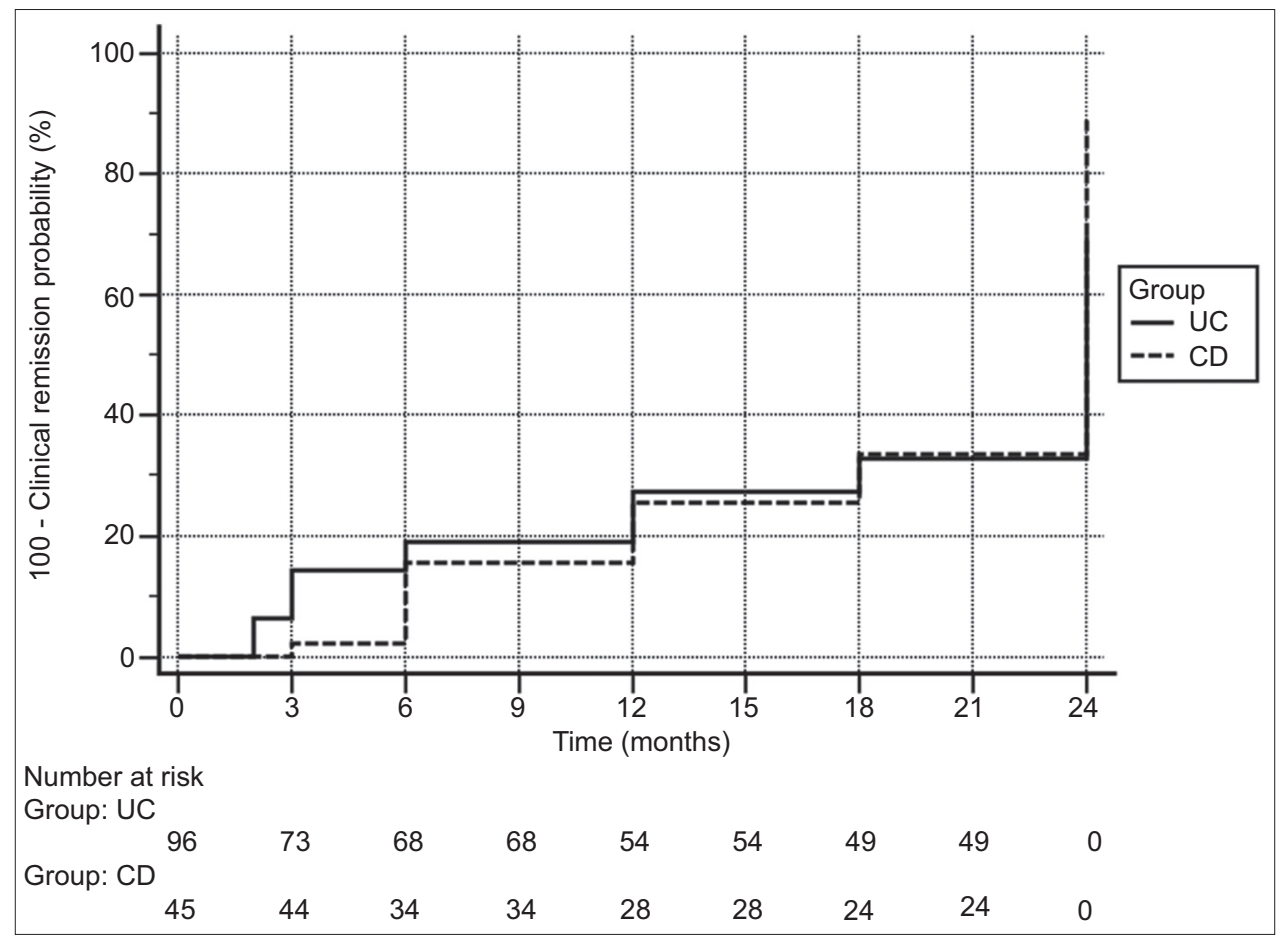

Figure 1 Estimated cumulative clinical remission probability during follow up in patients with ulcerative colitis (UC) or Crohn's disease (CD). Log-rank test

Table 2 Predictors of clinical remission

\begin{tabular}{|c|c|c|c|c|c|c|c|}
\hline \multirow[t]{2}{*}{ Factors } & \multicolumn{4}{|c|}{ Univariate Cox $\mathrm{PH}$ model } & \multicolumn{3}{|c|}{ Multivariate analysis Cox PH model } \\
\hline & $\chi^{2}$ & $\mathrm{P}$ & HR & $95 \% \mathrm{CI}$ & HR & $95 \% \mathrm{CI}$ & $\mathrm{P}$ \\
\hline UC vs. CD & 1.253 & 0.263 & 1.214 & 0.782 to 1.883 & - & - & - \\
\hline Sex, male & 0.134 & 0.714 & 1.064 & 0.700 to 1.616 & - & - & - \\
\hline Age $>40$ years & 11.355 & 0.001 & 1.773 & 1.119 to 2.807 & 0.590 & $0.386-0.904$ & 0.015 \\
\hline Disease duration $>5$ years & 0.858 & 0.354 & 0.856 & 0.565 to 1.295 & - & - & - \\
\hline No appendectomy & 0.936 & 0.333 & 1.322 & 0.690 to 2.533 & - & - & - \\
\hline Presence of comorbidities & 6.566 & 0.010 & 1.561 & 0.984 to 2.474 & 1.556 & $1.011-2.396$ & 0.044 \\
\hline Naïve to anti-TNF $\alpha$ & 13.475 & 0.000 & 1.959 & 1.286 to 2.986 & 1.815 & $1.145-2.878$ & 0.011 \\
\hline Anti-TNF $\alpha$ switch from originator & 2.289 & 0.084 & 0.658 & 0.389 to 1.119 & - & - & - \\
\hline
\end{tabular}

UC, ulcerative colitis; CD, Crohn disease; PH, proportional hazards; HR, hazard ratio; CI, confidence interval; TNF, tumor necrosis factor

Table 3 Outcomes of secondary end-points during follow up

\begin{tabular}{lcc}
\hline Outcomes & UC $(\mathrm{n}=96)$ & $\mathrm{CD}(\mathrm{n}=45)$ \\
\hline Clinical response & $84(87.5)$ & $38(84.4)$ \\
Previous anti-TNF $\alpha$ & $19 / 25(76.0)$ & $11 / 13(84.6)$ \\
Mucosal healing & $42 / 56(75.0)$ & $16 / 19(84.2)$ \\
Reduction in steroids & $93(96.9)$ & $44(97.8)$ \\
Surgery & $2(2.1)$ & $3(6.7)$
\end{tabular}

Data are given as number (percentage) of patients unless otherwise indicated $U C$, ulcerative colitis; $C D$ Crohn's disease
Biosimilar IFX CT-P13 has shown its efficacy and safety in the treatment of rheumatic disease $[9,10]$, and has been approved for all of the same indications as RMP, including CD and UC, in Europe, Japan and South Korea $[8,11,12]$.

Since the "extrapolation" of clinical data from rheumatic to gastrointestinal indications triggered a large debate, several observational "real world" studies are becoming available. To date, most of these studies found that biosimilar IFX CT-P13 was also effective and well-tolerated in IBD patients [13-23]. However, all of these studies were conducted in academic or tertiary IBD centers. Our previous pilot study found biosimilar 
IFX CT-P13 to be effective and well-tolerated in active UC outpatients [26]. This larger study confirms these results and raises several clinical considerations.

This is the first large study with a long-term follow up (24 months) conducted in Italy in primary IBD centers to assess the efficacy and safety of biosimilar IFX CT-P13. Looking at the primary endpoints, the first consideration is that biosimilar IFX CT-P13 is really effective and safe in real life, even when managed in primary IBD centers. A significant remission rate and a very high clinical response rate were obtained in our population, in both UC and CD subjects. Literature data showed that biosimilar IFX CT-P13 achieved remission in $50-80 \%$ of UC and CD patients, while a clinical response was recorded in 54-100\% of patients [13-23]. Our results are in line with these experiences, and better to the one recently reported by Fiorino et al, who described the real-life experience from using biosimilar IFX CT-P13 in Italian academic or tertiary IBD referral IBD centers [13]. It is likely that our results may be influenced by the less complex patients managed in primary IBD centers, which generally manage patients who do not require complex clinical and therapeutic approaches.

With respect to safety, we found biosimilar IFX CT-P13 to have an excellent safety profile, since we recorded an AE rate $<1 \%$. This result deserves an adequate analysis. From October 2015 to October 2017, a rapid increase in the utilization of biosimilar IFX CT-P13 was recorded across Italy [33]. However, this increase was also associated with an increase in the reports of AE induced by IFX biosimilars [33]. This seems to contrast with a recent study by Gonçalves et al, who found a similar antigenic profile for IFX originator and IFX biosimilar CT-P13 [34]. Finally, the recent PROSIT Italian cohort study found a $19 \%$ rate of AE [23]. As hypothesized for our efficacy results, the less complex patients managed in primary IBD centers may explain our excellent results concerning safety. The characteristics of our study group may also explain why comorbidity is not a risk factor for loss of response: probably comorbidities were not severe, and therefore were not able to negatively influence the course of the disease.

With respect to the secondary endpoints, biosimilar IFX CT-P13 shows an excellent high rate of achieving mucosal healing, clinical response and steroid sparing. Therefore, in our experience, biosimilar IFX CT-P13 seems to work as well as the originator [35] and better than other anti-TNFa medications such as adalimumab [36] and golimumab [37]. Of course, these comparisons must be made with appropriate reservations, since the populations enrolled are not the same, with different follow-up periods and different percentages of patients previously exposed to anti-TNFa.

Another finding that deserves some comment is that multivariate analysis found IFX CT-P13 to be more effective in patients older than 40 years and with comorbidities. This may seem counterintuitive, since we know that older age is a risk factor for lower treatment efficacy [38] and older people show a higher AE rate [39]. It is not easy to explain our results. The mean disease duration of the enrolled population was quite short (no more than 5 years): this could have played a positive role in their response to the treatment and in reducing the risk of AE despite the older age and the presence of comorbidities.
However, this does not fully explain the better response in older patients; thus, larger and longer studies are needed in this specific setting.

These excellent results of biosimilar IFX CT-P13 in achieving both primary and secondary endpoints lead to the last clinical consideration: namely, whether and when we can switch from Remicade' to Remsima' appropriately. This is a key point for clinical practice, because it may lead to significant cost-sparing. Switching from originator to biosimilar is generally advised in patients under stable remission with an IFX originator. Current literature data found switching from Remicade' to Remsima' safe and feasible in both pediatric and adult IBD patients $[13,28,40-43]$, though a recent systematic review recommends caution in switching from originator to biosimilar [44]. In our study group there were only few patients switched from IFX originator to biosimilar IFX CT-P13, and we did not find any significant difference between patients naïve to IFX and patients switching from IFX originator to IFX biosimilar with respect to achievement of remission. It is noteworthy to underscore that all our patients were under stable remission when they were switched to IFX biosimilar. This may explain the good results we observed in this subgroup of patients. However, the small number of patients does not allow us to draw definite conclusions.

The present study suffers from some limitations. The first is the retrospective design, which did not allow us to enroll patients with the same timing through the follow up, either clinical or endoscopic. The second is that only outpatients with mild-to-moderate disease were enrolled. Since this study

\section{Summary Box}

\section{What is already known:}

- Infliximab biosimilar CT-P13 is the first available biosimilar for the treatment of inflammatory bowel diseases (IBD)

- Short-term follow-up studies found infliximab biosimilar CT-P13 effective both in naïve patients and in those previously exposed to other anti-tumor necrosis factor (TNF) a agents

- Some real-life studies have investigated its efficacy and safety, but were performed in secondary/tertiary centers

\section{What the new findings are:}

- This is the first study conducted in primary IBD centers in Italy

- In this setting, over a long-term follow up, infliximab biosimilar CT-P13 seems to be effective both in naïve patients and in those with prior exposure to other anti-TNFa agents

- Infliximab biosimilar CT-P13 also seems to be safe over a long-term follow up 
was conducted by primary IBD centers, the patients managed were generally less complex and the majority of anti-TNFa prescriptions were subcutaneous anti-TNFa antibodies, since these are easier to use for outpatients. This amounts to a selection bias, which may have influenced the final results. It may also explain why Italian academic and referral IBD centers enrolled a large population on biosimilar IFX CT-P13 [23].

In conclusion, this large real-life cohort study from primary Italian IBD centers shows that biosimilar IFX CT-P13 is as effective and safe as the originator IFX in managing IBD outpatients. Longer real-life studies are needed to confirm the possibility of switching from IFX originator to IFX biosimilar without any loss of efficacy and safety.

\section{References}

1. Dignass A, Eliakim R, Magro F, et al. Second European evidencebased consensus on the diagnosis and management of ulcerative colitis part 1: definitions and diagnosis. J Crohns Colitis 2012;6:965-990.

2. Dignass A, Lindsay JO, Sturm A, et al. Second European evidence-based consensus on the diagnosis and management of ulcerative colitis part 2: current management. J Crohns Colitis 2012;6:991-1030.

3. Lichtenstein GR, Abreu MT, Cohen R, Tremaine W; American Gastroenterological Association. American Gastroenterological Association Institute technical review on corticosteroids, immunomodulators, and infliximab in inflammatory bowel disease. Gastroenterology 2006;130:940-987.

4. Norum J, Koldingsnes W, Aanes T, Antonsen MA, Florholmen J, Kondo M. The economic burden of TNFa inhibitors and other biologic treatments in Norway. Clinicoecon Outcomes Res 2011;3:73-78.

5. Rutgeerts P, Van Assche G, Vermeire S. Review article: Infliximab therapy for inflammatory bowel disease-seven years on. Aliment Pharmacol Ther 2006;23:451-463.

6. Blackstone EA, Fuhr JP Jr. Innovation and competition: will biosimilars succeed?: The creation of an FDA approval pathway for biosimilars is complex and fraught with hazard. Yes, innovation and market competition are at stake. But so are efficacy and patient safety. Biotechnol Health 2012;9:24-27.

7. World Health Organization. Expert committee on biological standardization. Geneva, 19 to 23 October 2009. Guidelines on evaluation of similar biotherapeutic products (SBPs). Available from: http://www.who.int/biologicals/areas/biological_ therapeutics/BIOTHERAPEUTICS_FOR_WEB_22APRIL2010. pdf [Accessed 10 April 2019].

8. European Medicines Agency. Committee for Medicinal Products for Human Use (CHMP). Assessment report: Remsima (infliximab). 2013. Available from: http://www.ema.europa.eu/ docs/en_GB/document_library/EPAR-Public_assessment_report/ human/002576/WC500151486.pdf [Accessed 10 April 2019].

9. Yoo DH, Hrycaj P, Miranda P, et al. A randomised, double-blind, parallel-group study to demonstrate equivalence in efficacy and safety of CT-P13 compared with innovator infliximab when coadministered with methotrexate in patients with active rheumatoid arthritis: the PLANETRA study. Ann Rheum Dis 2013;72:1613-1620.

10. Park W, Hrycaj P, Jeka S, et al. A randomised, double-blind, multicentre, parallel-group, prospective study comparing the pharmacokinetics, safety, and efficacy of CT-P13 and innovator infliximab in patients with ankylosing spondylitis: the PLANETAS study. Ann Rheum Dis 2013;72:1605-1612.

11. Generics and biosimilars initiative. Biosimilars approved in South Korea. 2015. Available from: http://gabionline.net/ Biosimilars/General/Biosimilars-approved-in-South-Korea [Accessed 10 April 2019].

12. Generics and biosimilars initiative. Biosimilars approved in Japan. 2015. Available from: http://gabionline.net/Biosimilars/General/ Biosimilars-approved-in-Japan [Accessed 10 April 2019].

13. Fiorino G, Manetti N, Armuzzi A, et al; PROSIT-BIO Cohort. The PROSIT-BIO Cohort: A prospective observational study of patients with inflammatory bowel disease treated with infliximab biosimilar. Inflamm Bowel Dis 2017;23:233-243.

14. Farkas K, Rutka M, Ferenci T, et al. Infliximab biosimilar CT-P13 therapy is effective and safe in maintaining remission in Crohn's disease and ulcerative colitis - experiences from a single center. Expert Opin Biol Ther 2017;17:1325-1332.

15. Gecse KB, Lovász BD, Farkas K, et al. Efficacy and safety of the biosimilar infliximab CT-P13 treatment in inflammatory bowel diseases: a prospective, multicentre, nationwide cohort. J Crohns Colitis 2016;10:133-140.

16. Jahnsen J, Detlie TE, Vatn S, Ricanek P. Biosimilar infliximab (CT-P13) in the treatment of inflammatory bowel disease: a Norwegian observational study. Expert Rev Gastroenterol Hepatol 2015;9(Suppl 1):45-52.

17. Jung YS, Park DI, Kim YH, et al. Efficacy and safety of CT-P13, a biosimilar of infliximab, in patients with inflammatory bowel disease: a retrospective multicenter study. J Gastroenterol Hepatol 2015;30:1705-1712.

18. Kang YS, Moon HH, Lee SE, Lim YJ, Kang HW. Clinical experience of the use of CT-P13, a biosimilar to infliximab in patients with inflammatory bowel disease: a case series. Dig Dis Sci 2015;60:951-956.

19. Keil R, Wasserbauer M, Zádorová Z, et al. Clinical monitoring: infliximab biosimilar CT-P13 in the treatment of Crohn's disease and ulcerative colitis. Scand J Gastroenterol 2016;51:1062-1068.

20. Park SH, Kim YH, Lee JH, et al. Post-marketing study of biosimilar infliximab (CT-P13) to evaluate its safety and efficacy in Korea. Expert Rev Gastroenterol Hepatol 2015;9(Suppl 1):35-44.

21. Sieczkowska J, Jarzębicka D, Banaszkiewicz A, et al. Switching between infliximab originator and biosimilar in pediatric patients with inflammatory bowel disease: preliminary observations. J Crohns Colitis 2016;10:127-132.

22. Danese S, Fiorino G, Raine T, et al. ECCO Position statement on the use of biosimilars for inflammatory bowel disease-an update. J Crohns Colitis 2017;11:26-34.

23. Armuzzi A, Fiorino G, Variola A, et al; PROSIT Investigators. The PROSIT cohort of infliximab biosimilar in IBD: a prolonged follow-up on the effectiveness and safety across Italy. Inflamm Bowel Dis 2019;25:568-579.

24. Classificazione del medicinale per uso umano "Inflectra", approvato con procedura centralizzata. Gazzetta Ufficiale della Repubblica Italiana 2014;17:11-14.

25. Regime di rimborsabilità e prezzo del medicinale per uso umano "Remsima" (infliximab), autorizzata con procedura centralizzata europea dalla Commissione Europea. Gazzetta Ufficiale della Repubblica Italiana 2014;302:42-43.

26. Tursi A, Allegretta L, Chiri S, et al. Effectiveness and safety of infliximab biosimilar CT-P13 in treating ulcerative colitis: a real-life experience in IBD primary centers. Minerva Gastroenterol Dietol 2017;63:313-318.

27. Satsangi J, Silverberg MS, Vermeire S, Colombel JF. The Montreal classification of inflammatory bowel disease: controversies, consensus, and implications. Gut 2006;55:749-753.

28. Schroeder KW, Tremaine WJ, Ilstrup DM. Coated oral 
5-aminosalcylic acid therapy for mildly to moderately active ulcerative colitis. N Engl J Med 1987;317:1625-1629.

29. Best WR. Predicting the Crohn's disease activity index from the Harvey-Bradshaw Index. Inflamm Bowel Dis 2006;12:304-310.

30. Daperno M, D'Haens G, Van Assche G, et al. Development and validation of a new, simplified endoscopic activity score for Crohn's disease: the SES-CD. Gastrointest Endosc 2004;60:505-512.

31. Moskovitz DN, Daperno M, Van Assche G. Defining and validating cut-offs for the Simple Endoscopic Score for Crohn's Disease. Gastroenterology 2007;132:S1097.

32. Colombel JF, Sandborn WJ, Reinisch W, et al; SONIC Study Group. Infliximab, azathioprine, or combination therapy for Crohn's disease. N Engl J Med 2010;362:1383-1395.

33. Scavone C, Sessa M, Clementi E, et al. Real world data on the utilization pattern and safety profile of infliximab originator versus biosimilars in Italy: a multiregional study. BioDrugs 2018;32:607-617.

34. Goncalves J, Santos M, Acurcio R, et al. Antigenic response to CT-P13 and infliximab originator in inflammatory bowel disease patients shows similar epitope recognition. Aliment Pharmacol Ther 2018;48:507-522.

35. Tursi A, Elisei W, Picchio M, et al. Managing ambulatory ulcerative colitis patients with infliximab: a long term followup study in primary gastroenterology centers. Eur J Intern Med 2014;25:757-761.

36. Tursi A, Elisei W, Faggiani R, et al. Effectiveness and safety of adalimumab to treat outpatient ulcerative colitis: A real-life multicenter, observational study in primary inflammatory bowel disease centers. Medicine (Baltimore) 2018;97:e11897.

37. Tursi A, Allegretta L, Buccianti N, et al. Effectiveness and safety of golimumab in treating outpatient ulcerative colitis: a real-life prospective, multicentre, observational study in primary inflammatory bowel diseases centers. J Gastrointestin Liver Dis 2017;26:239-244.

38. Charpentier C, Salleron J, Savoye G, et al. Natural history of elderly-onset inflammatory bowel disease: a population-based cohort study. Gut 2014;63:423-432.

39. Cottone M, Kohn A, Daperno M, et al. Advanced age is an independent risk factor for severe infections and mortality in patients given anti-tumor necrosis factor therapy for inflammatory bowel disease. Clin Gastroenterol Hepatol 2011;9:30-35.

40. Smits LJ, Derikx LA, de Jong DJ, et al. Clinical outcomes following a switch from Remicade to the Biosimilar CT-P13 in inflammatory bowel disease patients: a prospective observational cohort study. J Crohns Colitis 2016;10:1287-1293.

41. Buer LC, Moum BA, Cvancarova M, Warren DJ, Medhus AW, Høivik ML. Switching from Remicade ${ }^{\curvearrowleft}$ to Remsima ${ }^{\circ}$ is well tolerated and feasible: a prospective, open-label study. J Crohns Colitis 2017;11:297-304.

42. Jørgensen KK, Olsen IC, Goll GL, et al; NOR-SWITCH study group. Switching from originator infliximab to biosimilar CT-P13 compared with maintained treatment with originator infliximab (NOR-SWITCH): a 52-week, randomised, double-blind, noninferiority trial. Lancet 2017;389:2304-2316.

43. Bergqvist V, Kadivar M, Molin D, et al. Switching from originator infliximab to the biosimilar CT-P13 in 313 patients with inflammatory bowel disease. Therap $A d v$ Gastroenterol 2018;11:1756284818801244

44. Feagan BG, Lam G, Ma C, Lichtenstein GR. Systematic review: efficacy and safety of switching patients between reference and biosimilar infliximab. Aliment Pharmacol Ther 2019;49:31-40. 